\title{
Observational evidence for the generation of a 4-day oscillation in the low-latitude middle atmosphere associated with an anomalous stratospheric cooling
}

\author{
V. Deepa, G. Ramkumar, and K. K. Kumar \\ Space Physics Laboratory, Vikram Sarabhai Space Centre, Thiruvananthapuram-695022, India \\ Received: 1 March 2007 - Revised: 2 August 2007 - Accepted: 10 August 2007 - Published: 2 October 2007
}

\begin{abstract}
Altitude profiles of temperature in the stratosphere and lower mesosphere over Gadanki $\left(13.5^{\circ} \mathrm{N}, 79.2^{\circ} \mathrm{E}\right)$, based on lidar observations during the Equatorial Wave Study campaign (29 February-2 April 2000), showed an anomalous cooling of the stratosphere, lasting for about 4 5 days. Immediately following this stratospheric cooling, a prominent $\sim 4$-day period oscillation is observed in the zonal, as well as meridional wind in the $30-50 \mathrm{~km}$ altitude region, obtained from simultaneous rocketsonde and balloon wind measurements. The amplitude of this wave is in the range of $5-15 \mathrm{~ms}^{-1}$ in this altitude region. The altitude profiles of phase of this 4-day oscillation show a constant phase with height indicating that the wave is not propagating vertically. The causative mechanism for the sudden cooling is investigated by examining the day-to-day variation in the total atmospheric column ozone. Zonal and meridional wind components of this oscillation are approximately in quadrature phase, with zonal wind leading the meridional wind. Strikingly, while the 4-day wave is clearly observable in the zonal and meridional winds, it is almost absent in the temperature.
\end{abstract}

Keywords. Ionosphere (Wave propagation) - Meteorology and atmospheric dynamics (Middle atmosphere dynamics; Waves and tides)

\section{Introduction}

Atmospheric waves are excited either by thermal or dynamic effects. The mechanism for the forcing of the atmospheric wave, i.e. the generation of the initial disturbance in the atmospheric variables, can vary. The dynamical effects that generate atmospheric waves include topography, wind shear, wave-wave interaction, whereas the thermal effects include

Correspondence to: V. Deepa

(v_deepa2005@yahoo.com) latent heat released by clouds, absorption of radiation by water vapour and the ozone layer, temperature contrasts between continents and oceans and differential heating of the atmosphere.

One aspect that makes the stratospheric studies important is the presence of the ozone layer. The total amount of ozone in a vertical column of the atmosphere is essentially determined by its lower-stratospheric content. Now it is well established that $90 \%$ of the total atmospheric ozone is located in the stratosphere. Ozone strongly absorbs ultraviolet (UV) solar radiation and is a significant diabatic heat source for the stratosphere. Reduction in stratospheric ozone leads to a reduction in solar ultraviolet heating and might produce a cooling of this region (Ghazi, 1974; Imre, 1996; Ramaswamy, 1996; Ramaswamy et al., 2001; Hare et al., 2004; Steinbrecht, 2006).

The thermal structure of the atmosphere is very important for both the generation and propagation of atmospheric waves. For example, the atmospheric heating produced by the absorption of solar radiation by ozone and water vapor generates atmospheric tides (Chapman and Lindzen, 1970). The gravity wave generation due to differential heating during solar eclipse has been addressed in a number of theoretical and observational studies (Chimonas and Hines, 1970; Anderson et al., 1972; Reddy, 1982; Fritts and Luo; 1993). Chimonas and Hines (1970) explained that the atmospheric region around $45 \mathrm{~km}$, in which the daily heating rate due to the absorption of solar UV radiation is a maximum, could become cooled significantly during the solar eclipse because of a reduction in the content of the UV radiation. They suggested that the cooling of the stratospheric air mass could generate acoustic gravity waves. All these studies suggested that the cooling of the stratosphere due to ozone depletion can act as a perturbation under the mean atmospheric conditions, which can lead to the generation/modification of atmospheric waves. 
In this paper, we present observational evidence for the insitu generation of atmospheric waves that is observed just after a sudden cooling of the stratosphere over the tropical middle atmosphere. For this study the altitude profiles of temperature derived from Rayleigh lidar (stratosphere and mesosphere) and Mesosphere-Stratosphere-Troposphere (MST) radar (troposphere) observations, and the zonal and meridional winds in the $0-65 \mathrm{~km}$ altitude region obtained from balloon and rocket measurements from 29 February to 2 April 2000 are used. The role of ozone in the causative mechanism of the sudden cooling in the stratosphere is investigated based on total atmospheric column ozone observations obtained from satellite-based Total Ozone Monitoring Spectrometer (TOMS) data. Section 2 provides the details of data used for the present study, while the results are presented in Sect. 3. Section 4 has the discussion on observed results and summary of findings is given in Sect. 5 .

\section{Data}

Daily altitude profiles of temperature in the 3 to $65 \mathrm{~km}$ over Gadanki $\left(13.5^{\circ} \mathrm{N}, 79.2^{\circ} \mathrm{E}\right)$ and wind in the altitude region of 0 to $65 \mathrm{~km}$ over a very nearby location, the Shriharikota Range (SHAR) $\left(13.7^{\circ} \mathrm{N}, 80.2^{\circ} \mathrm{E}\right)$, are used in the present study. These observations were carried out as part of the equatorial wave studies campaign (Sasi et al., 2003). The temperatures in the 3 to $22 \mathrm{~km}$ altitude range are derived from the vertical wind data of $\sim 2$-h duration (from 20:00 IST22:00 IST) following the method derived by Revathy et al. (1996). The standard error of these measurements is $0.7 \mathrm{~K}$ at $7 \mathrm{~km}$ and $1.6 \mathrm{~K}$ at $20 \mathrm{~km}$ (Revathy et al., 1998). The altitude profiles of temperature in the altitude region of 27 to $65 \mathrm{~km}$ over Gadanki are obtained from the Rayleigh Lidar observations (Parameswaran et al., 2000). Lidar employs an Nd:YAG laser, operated at its harmonic wavelength of $532 \mathrm{~nm}$, as the transmitter. The pulse energy is $0.4 \mathrm{~J}$ and pulse width is $7 \mathrm{~ns}$. The lidar is operated with an altitude resolution of $300 \mathrm{~m}$ and a pulse repetition frequency of $20 \mathrm{~Hz}$. The system provides backscattered signals, which are integrated over 5000 transmitted pulses, corresponding to a temporal averaging of $250 \mathrm{~s}$ and these form the basic raw data for further analysis. Estimation of temperature from lidar data and the sources of errors are explained in detail by Parameswaran et al. (2000). The statistical error due to signal variance is $\sim 1 \mathrm{~K}$ in the lower altitudes $(30-50 \mathrm{~km})$ and it increases with altitude $(\sim 2.5 \mathrm{~K}$ at $65 \mathrm{~km})$. In the present study, the lidar raw data are integrated in height and time such that the temperature profiles are derived with a height resolution of $900 \mathrm{~m}$ and a time resolution of $12.5 \mathrm{~min}$, in order to reduce the statistical errors. The reference altitude required for the lidar inversion is taken as $80 \mathrm{~km}$ (Sasi and Senguptha, 1986). The lidar observations were made for $\sim 3 \mathrm{~h}$ (from 20:00 IST to 23:00 IST) from 29 February to 2 April 2000. From these observations daily mean temperature profiles are obtained.
There is no lidar data on 5, 6 and 26 March 2000, due to bad weather conditions. In order to minimize the uncertainty due to various errors, lidar-derived temperature in the $27-65 \mathrm{~km}$ altitude region only is used in the present study.

The daily horizontal wind data were collected using RH200 rockets and high altitude balloons over a nearby location, SHAR, from 29 February to 2 April 2000. There were daily rocket and balloon flights. The total number of rocket and balloon flights is 34 . The rocket measured wind data is available in the $25-65 \mathrm{~km}$ altitude region with a vertical resolution of $1 \mathrm{~km}$ and balloon data is available from the surface to $25 \mathrm{~km}$, with a vertical resolution of $0.3 \mathrm{~km}$.

Total atmospheric column ozone measurements are obtained from Total Ozone Monitoring Spectrometer (TOMS) data, which provide the total ozone values with a geographical resolution of $1^{\circ}$ latitude $\times 1.25^{\circ}$ longitude. TOMS ozone data are taken from the website http://jwocky.gsfc. nasa.gov/eptoms/ep.html. To obtain the mean total ozone value around the region of study, these data are averaged over $3^{\circ}$ latitude $\times 3.75^{\circ}$ longitude.

\section{Results}

The time-height variation of temperature fluctuations (daily mean temperature minus the mean temperature during the period of observation) during the period from 29 February to 2 April 2000 is shown in Fig. 1a. Temperature fluctuations are available in the 3 to $65 \mathrm{~km}$ altitude region, except for a gap in the altitude region of 22 to $27 \mathrm{~km}$, where both MST radar and lidar measurements of temperature are not possible. White horizontal and vertical bands in Fig. 1a represent the gap in the data. There are no lidar data on 5, 6 and 26 March 2000 and no radar data on 17 March 2000. A strong cooling (up to $\sim 5-20 \mathrm{~K}$ ) is clearly observed in the $10-50 \mathrm{~km}$ altitude region from day number 4 to 8 (i.e. from 3 March to 7 March 2000). It may be noted that the temperature measurements in the altitude region, where cooling is observed, were carried out by different observational techniques (i.e. MST radar in the troposphere and Rayleigh lidar in the stratosphere/mesosphere). The maximum anomaly with a magnitude of $\sim 25 \mathrm{~K}$ is observed on 7 March in the altitude region of $27-36 \mathrm{~km}$.

The causative mechanism for the sudden cooling is investigated by examining the day-to-day variation in the total atmospheric column ozone over a $3^{\circ} \times 3.75^{\circ}$ geographical area around Gadanki, which is shown in Fig. 1b. The total atmospheric column ozone value is less ( 255 Dobson Units) during the first few days of observation (up to day number 8). From day number 8 onwards, the total ozone values start increasing and temperature fluctuations also become positive. The difference between the total ozone between day number 8 and day number 16 is about 18 DU. In general, a positive correlation can be observed between stratospheric temperature and total atmospheric column ozone. Since the major contribution to the total atmospheric column ozone 

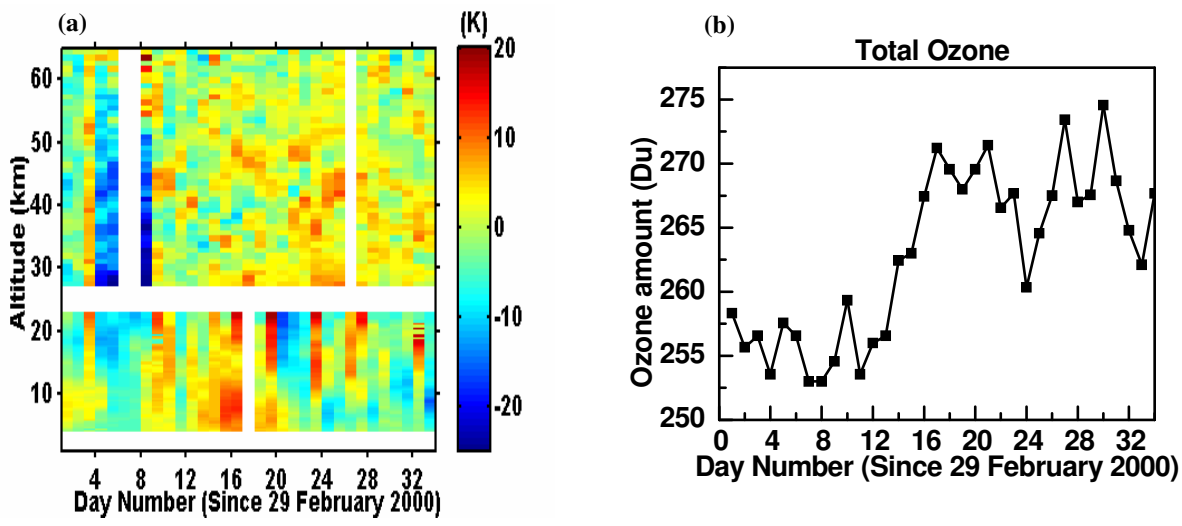

Fig. 1. (a) Time-height variation of temperature fluctuations (b) Total atmospheric column ozone data (TOMS data) during 29 February to 2 April 2000.
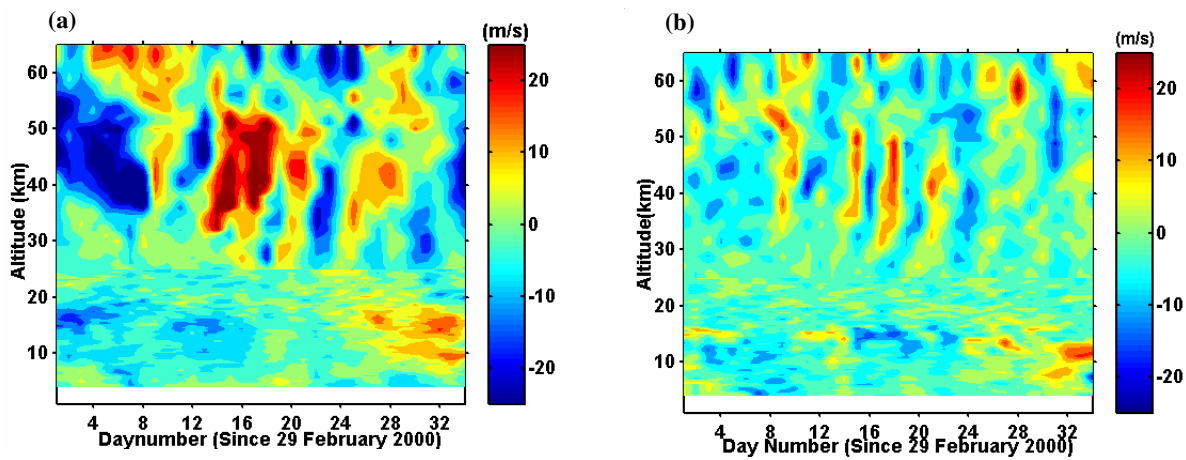

Fig. 2. Time-height section of (a) zonal and (b) meridional wind fluctuations during 29 February to 2 April 2000.

is from the stratospheric ozone, the anomalous cooling observed is likely to be a consequence of the reduction in the absorption of solar ultra violet radiation due to the reduction in the stratospheric ozone.

To study the effect of this anomalous cooling on the stratospheric dynamics, the zonal and meridional wind fluctuations during the same period used for the observation of temperature are analysed and are shown in Figs. 2a and b, respectively. Immediately following the period of cooling (3-7 March), oscillations with a periodicity of $\sim 4$ days are observed in the zonal and meridional winds in the altitude region of $30-50 \mathrm{~km}$. These oscillations are found to possess almost the same phase over the entire altitude region where they are observed. In order to study the characteristics of these oscillations, the zonal and meridional wind fluctuations are subjected to wavelet analysis. Significant amplitudes are observed at wave periods 16-day and 12-day throughout the period of observation in the case of zonal wind, while these waves are almost absent in the meridional wind. This indicates that these 16-day and 12-day oscillations are due to Kelvin waves. Detailed characteristics of these equatorial waves observed during this period of observation are reported elsewhere (Sasi et al., 2003) and hence are not reproduced here.
Following the period of cooling (3-7 March), prominent oscillations with a periodicity of $\sim 4$ days are observed both in zonal and meridional winds. These oscillations last for at least 5 cycles. Since the zonal component of these oscillations is superimposed over a large background mean zonal wind, it is less evident in the zonal wind than that of the meridional wind. All these oscillations appear as "pillar-like" with negligible altitude variation in phase. The largest amplitude of this oscillation appears to be occurring at $\sim 40 \mathrm{~km}$. The absence of a short period fluctuation in the zonal and meridional wind before the cooling period is remarkable and the above-discussed "pillar-like oscillations" appear suddenly after the cooling event.

Another important feature observed in Figs. $2 \mathrm{a}$ and $\mathrm{b}$ is that the altitude region where the 4-day oscillation occurs descends with time. In the beginning the 4-day oscillation appears between 35 and $55 \mathrm{~km}$, while towards the last phase (around day number 24) this oscillation is prominently observed in the $25-45 \mathrm{~km}$ altitude region. Strikingly, a clear signature of any such 4-day wave is absent in the temperature fluctuations over this altitude region (Fig. 1a).

Since the "pillar-like" oscillations are most prominently observed during 8 to 27 March, the zonal and meridional wind fluctuations during this period are subjected to Fourier 

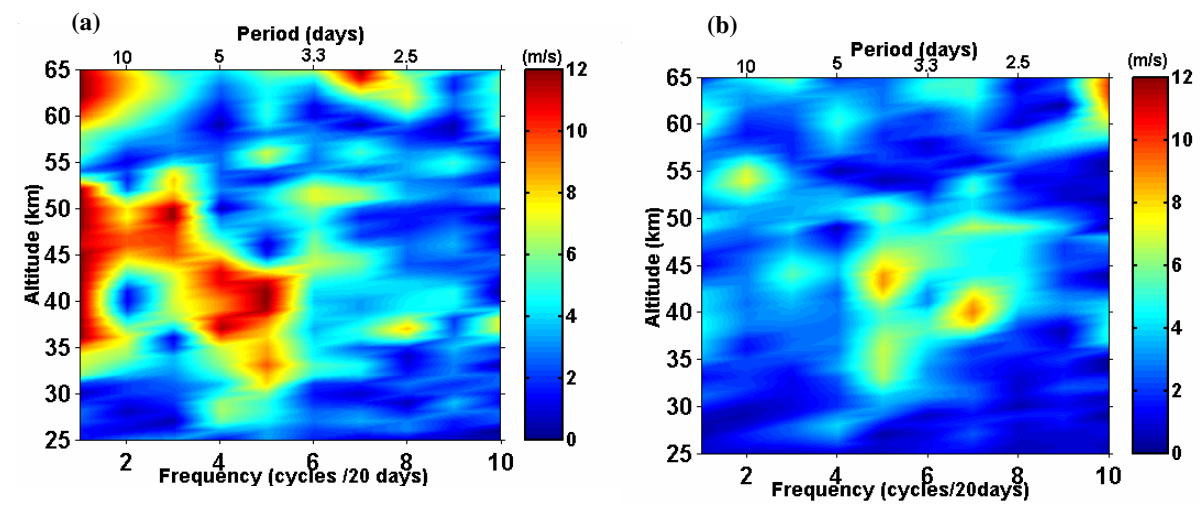

Fig. 3. Height-frequency plot of amplitudes of (a) zonal and (b) meridional wind fluctuations.

(a)

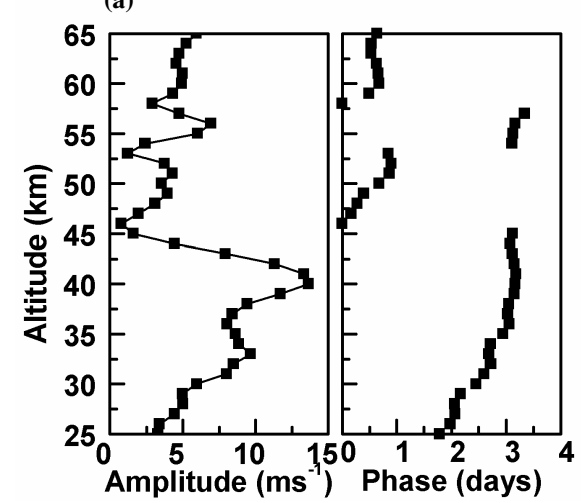

(b)

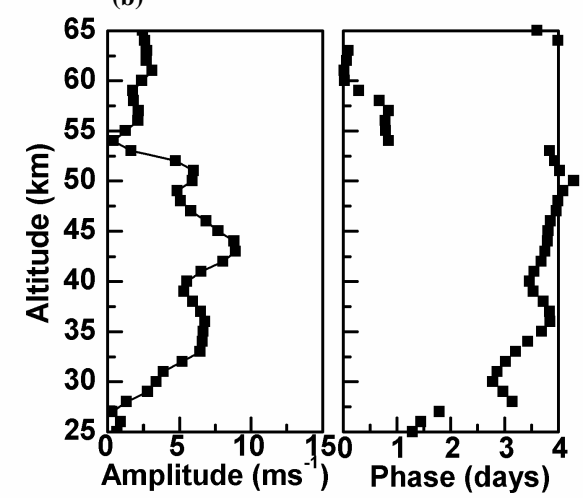

Fig. 4. Vertical profile of amplitude and phase of 4-day wave (a) zonal wind and (b) meridional wind.

analysis, to clearly delineate the properties of these oscillations. Figures $3 \mathrm{a}$ and $\mathrm{b}$ show the contour plots of amplitudes of the oscillations in zonal and meridional wind fluctuations, respectively. In the zonal wind a 20-day periodicity is prominent in the altitude region of 35 to $65 \mathrm{~km}$. In the 45 to $60 \mathrm{~km}$ region, a 6-day periodic oscillation is prominent. It can be seen that in the altitude region of 30 to $45 \mathrm{~km}, 5$ - and 4-day periodic oscillations are prominent. In the case of the meridional wind, a 4-day periodicity in the altitude region of 30 to $50 \mathrm{~km}$ and a 3-day periodicity in the altitude region of 40 to $50 \mathrm{~km}$ are both prominent. The 4-day periodicity in the region of 30 to $50 \mathrm{~km}$ is observed in both zonal and meridional winds.

The vertical profile of the amplitude and phase of the 4day oscillation observed in the zonal and meridional winds is shown in Figs. 4a and b, respectively. The maximum amplitude of the zonal component of the 4-day oscillation is $14 \mathrm{~ms}^{-1}$, which is observed at an altitude of $40 \mathrm{~km}$. A maximum amplitude of $8.5 \mathrm{~ms}^{-1}$ is observed for the meridional component at $44 \mathrm{~km}$. Both in the zonal and meridional components, the phase is constant with height over the entire altitude region in which the wave has a significant amplitude $(30-45 \mathrm{~km})$, indicating that the wave is not propagating ver- tically. The zonal and meridional components are in quadrature phase, with the zonal component leading the meridional component.

\section{Discussion}

This study provides the observational evidence for the insitu generation of atmospheric waves by anomalous perturbations in the temperature fields in the stratosphere. It is found that a positive correlation exists between total atmospheric column ozone and stratospheric temperature. A reduction of about $18 \mathrm{DU}$ is observed in the total atmospheric column ozone during the period of occurrence of anomalous cooling. There are a number of studies carried out using long-term total ozone observations from satellite-based ozone measurements and stratospheric temperature, which reveal a positive correlation between the two (Ghazi, 1974; Ramaswamy et al., 1996, 2001; Steinbrecht et al., 2006). Ozone introduces a nonuniform, space-time cooling (Ramswamy et al., 2001), which can lead to differential heating of the various regions of the atmosphere. This differential heating will generate atmospheric waves. 
(a)

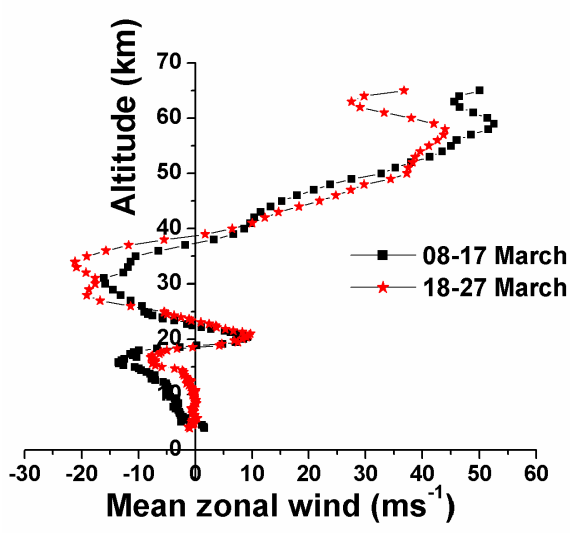

(b)

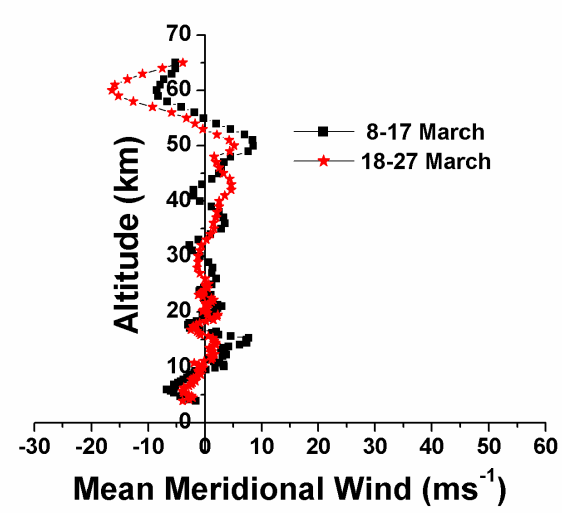

Fig. 5. Vertical profiles of mean (a) zonal and (b) meridional winds during 8-17 March 2000 and 18-27 March 2000.

Immediately following the anomalous cooling, a prominent oscillation with a period of $\sim 4$-days is observed both in the zonal and meridional winds in the altitude region of $30-45 \mathrm{~km}$. The maximum amplitude of this 4-day oscillation is $15 \mathrm{~ms}^{-1}$ in the zonal wind and $8.5 \mathrm{~ms}^{-1}$ in the meridional wind, which occurs at $\sim 40 \mathrm{~km}$ and at $\sim 45 \mathrm{~km}$, respectively. There is a negligible phase change with altitude in the region where a significant amplitude is observed. The zonal and meridional components of these oscillations are in quadrature phase, with the zonal component leading the meridional component. It appears that the 4-day oscillation is generated by the anomalous cooling in the stratosphere, which resides in the source region itself without any vertical propagation. Strikingly, the altitude of occurrence of this oscillation descends with time.

The mean zonal and meridional winds obtained during the first and second half of the period of occurrence of the 4-day oscillation (i.e. mean wind during 8-17 March 2000 and 1827 March 2000) are shown in Figs. 5a and b, respectively. Some of the characteristics of the 4-day oscillation observed in the present study, such as the wave period, the quadrature phase relationship and the amplitudes of the zonal and meridional wind components, are similar to that of Rossby Gravity (RG) waves. However, the absence of any prominent signature of the wave in temperature and the absence of any vertical propagation observed in this wave are not characteristic of RG waves. It may also be noted that the "pillar-like" structure descends with time (Fig. 2), despite the fact that the mean wind in the 40-60 km altitude region during the second half of observation is more eastward, which is favorable for the sustenance and propagation of RG waves.

The localized cooling that occurred in the stratosphere and troposphere over the region of study might have produced differential heating in that area. This differential heating can act as a perturbation for the generation of atmospheric oscillation. There are other possibilities for the generation of the observed 4-day oscillation, such as horizontal transports or intrusions in the subtropical barrier and equatorward refraction of planetary waves. During northern fall through spring, the regions of equatorial westerlies exist over the Pacific and Atlantic Oceans. These westerly ducts will sometimes be responsible for the cross-equatorial propagation of Rossby waves (Webster and Holton, 1982; Tomas and Webster, 1994; Yang and Hoskins, 1996; Ortland, 1997; Waugh and Polvani, 2000; Horinouchi et al., 2000). Another possibility is the equatorward refraction of planetary waves due to an enhanced temperature gradient. The altitude and latitudinal distribution of ozone depletion impacts the dynamical response in the global stratosphere and is a major factor in determining the meridional distribution of temperature changes. If the ozone changes are uniform with latitude, there would be a radiatively-induced cooling of the lower stratosphere, maximized in the tropics, with warming in the higher latitudes (Ramaswamy et al., 2001). Earlier studies present the possibility of refraction of planetary waves towards the equator, due to enhanced meridional temperature gradient (Hu and Tung, 2003; Hartman et al., 2000; Kodera, 1994; Kodera and Yamazaki, 1994). Hu and Tung (2003) suggest that during late winter, due to ozone depletion in the Arctic, there will be an enhanced meridional temperature gradient near the subpolar stratosphere, which leads to a strengthening of westerly winds. The strengthened winds refract planetary waves toward low latitudes and cause a reduction in wave activity of high latitudes. Studies of Kodera (1994) and Kodera and Yamazaki (1994) show that the cooling of the polar stratosphere can cause a meridional temperature gradient and equatorward refraction of stationary planetary waves. The absence of the horizontal wind data from other locations in the same altitude region, in order to investigate the meridional cross section or variation of their perturbation, prevents the further examination of these possibilities. 
However, the present study presents a rather rare case of in-situ generation of a vertically nonpropagating atmospheric wave that is clearly associated with a cooling of the atmospheric region between $10-55 \mathrm{~km}$, though the genesis of this wave cannot be unambiguously identified. Further observational and modeling studies are required for the identification of the causative mechanism of the observed waves.

\section{Summary}

An anomalous cooling, which lasted for 5 days, was observed in the upper troposphere and stratosphere in the temperature profiles obtained from Lidar and MST radar. The cooling appears to have occurred as a consequence of a reduction in the total atmospheric column ozone. Immediately following this anomalous cooling, a 4-day wave with little vertical phase propagation was observed in both zonal and meridional winds. While some of the characteristics of this wave are similar to RG waves, the absence of the vertical propagation and the absence of the temperature fluctuation are uncharacteristic of RG waves. While these types of oscillations can also be manifested as a result of the horizontal transport of the extratropical system, the absence of data to study the meridional cross section of these waves prevents further examination of this aspect. Strikingly, the period of this oscillation corresponds to the period of anomalous cooling in the 20-50 altitude region. This also suggests the possibility that in-situ generation of the wave is associated with this large cooling. Further studies are required for the identification of the causative mechanism of the observed waves.

Acknowledgements. The present study is based on the data collected during the Equatorial Wave Studies (EWS) campaign. The authors are thankful to the support provided by the technical and scientific personnel of National Atmospheric Research Laboratory (NARL) and SHAR for conducting the EWS campaign. The authors acknowledge the Goddard Space Flight Center for making available the total atmospheric column ozone data (TOMS data) in the website. The first author, V. Deepa, would like to acknowledge her gratitude to ISRO for providing the Research Associate position in Space Physics Laboratory and also thank K. Rajeev for useful discussions and guidance. Valuable suggestions by an anonymous reviewer has resulted in significant improvement in the quality of this manuscript.

Topical Editor U.-P. Hoppe thanks one anonymous referee for her/his help in evaluating this paper.

\section{References}

Anderson, R. C., Keefer, D. R., and Meyers, O. E.: Atmospheric pressure and temperature changes during the 7 March 1970 solar eclipse, J. Atmos. Sci., 29, 583-587, 1972.

Chapman, S. and Lindzen, R. S.: Atmospheric tides, D.Reidel, Norwell, Mass, 1970.
Chimonas, G. and Hines, C. O.: Atmospheric gravity waves induced by a solar eclipse, J. Geophys. Res. Space Phys., 75, 875889, 1970.

Fritts, D. C. and Luo, Z.: Gravity wave forcing in the middle atmosphere due to reduced ozone heating during a solar eclipse, J. Geophys. Res., 98, 3011-3021, 1993.

Ghazi, A.: Nimbus 4 Observations of changes in total ozone and stratospheric temperatures during a sudden warming, J. Atmos. Sci. 31, 2197-2206, 1974.

Hare, S. H. E., Gray, L. J., Lahoz, W. A., O’Neill, A., and Steenman-Clark, L.: Can stratospheric temperature trends be attributed to ozone depletion?, J. Geophys. Res., 109, D05111, doi:10.1029/2003JD003897, 2004.

Hartmann, D. L., Wallace, J. M., Limpasuvan, V., Thomson, D. W. J., and Holton, J. R.: Can ozone depletion and greenhouse warming interact to produce rapid climate change?, Proc. Natl. Acad. Sci., 97, 1412-1417, 2000.

Horinouchi, T., Sassi, F., and Boville, B. A.: Synoptic-scale Rossby waves and the geographic distribution of lateral transport routes between the tropics and the extra tropics in the lower stratosphere, J. Geophys. Res., 105, 26 579-26 592, 2000.

Hu, Y. and Tung, K. K.: Possible ozone-induced long term changes in planetary wave activity in late winter, J. Climate, 16, 30273038, 2003.

Imre, D. G.: Three dimensional pattern in temperature trends: signature for ozone depletion of green house gases?, American Geophysical Union 1996 Fall Meeting, San Francisco, CA, 15-19 December 1996.

Kodera, K.: Influence of volcanic eruptions on the troposphere through stratospheric dynamical processes in the northern hemisphere winter, J. Geophys. Res., 99, 1273-1282,1994.

Kodera, K. and Yamazaki, K.: A possible influence of recent polar stratospheric coolings on the troposphere in the Northern Hemisphere winter, Geophys. Res. Lett., 21, 809-812, 1994.

Ortland, D. A.: Rossby wave propagation into the tropical stratosphere observed by the High Resolution Doppler Imager, Geophys. Res. Lett., 24, 1999-2002, 1997.

Parameswaran, K., Sasi, M. N., Ramkumar, G., Nair, P. R., Deepa, V., et al.: Altitude profiles of temperature from 4 to $80 \mathrm{~km}$ over the tropics from MST radar and lidar, J. Atmos. Sol. Terr. Phys., 62, 1327-1337, 2000.

Ramaswamy, V., Schwarzkopf, M. D., and Randel, W.: Fingerprint of ozone depletion in the spatial and temporal pattern of recent lower-stratospheric cooling, Nature, 382, 616-618, 1996.

Ramaswamy, V., Chanin, M.-L., Angell, J., Barnet, J., et al.: Stratospheric temperature trends: observations and model simulations, Rev. Geophys., 39, 71-122, 2001.

Reddy, C. A.: Atmospheric pressure waves generated by solar eclipses, Proc. Indian Natl. Sci. Acad, 48A, 356-369, 1982.

Revathy, K., Prabhakaran Nair, S. R., and Krishnamurthy, B. V.: Deduction of temperature profiles from MST radar observations of vertical wind, Geophys. Res. Lett., 23, 285-288, 1996.

Revathy, K., Prabhakaran Nair, S. R., and Krishnamurthy, B. V.: Estimation of error in the determination of temperature using MST radar, Ind. J. Radio Space Phys., 27, 241-243, 1998.

Sasi, M. N. and Senguptha, K.: A model Equatorial Atmosphere over the Indian Zone from 0 to $80 \mathrm{~km}$, Sci. Rep., ISRO:VSSC:SR:19:72, 1986.

Sasi, M. N., Krishnamurthy, B. V., Ramkumar, G., Satheesan, K., 
et al.: A study of equatorial wave characteristics using rockets, balloons, lidar and radar, Adv. Space Res., 32, 813-818, 2003.

Steinbrecht, W., Habler, B., Bruhl, M., Dameris, M. A., Giorgetta, M. A., Grewe, V., Manzini, E., Matthes, S., Schnad, C., and Winkler, P.: Interannual variation patterns of total ozone and lower stratospheric temperature in observations and model simulations, Atmos. Chem. Phys., 6, 349-374, 2006, http://www.atmos-chem-phys.net/6/349/2006/.

Thomas, R. and Webster, P. J.: Horizontal and vertical structure of cross-equatorial wave propagation, J. Atmos. Sci., 51, 14171430, 1994.
Waugh, D. W. and Polvani, L. M.: Climatology of intrusions into the tropical upper troposphere, Geophys. Res. Lett., 27, 38573860, 2000.

Webster, P. J. and Holton, J. R.: Cross-sectional response to middlelatitude forcing in a zonally varying basic state, J. Atmos. Sci., 39, 722-733, 1982.

Yang, G. Y. and Hoskins, B. J.: Propagation of Rossby waves of nonzero frequency, J. Atmos. Sci., 53, 2365-2378, 1996. 